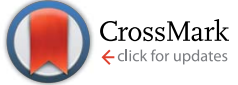

Cite this: RSC Adv., 2016, 6, 66360

\section{Electrochemical and electromechanical properties of superior-performance hybrid polymer actuators exhibiting synergistic effects due to manganese oxide and multi-walled carbon nanotubes on various ionic liquids $\uparrow$}

\begin{abstract}
Naohiro Terasawa* and Kinji Asaka
The electrochemical and electromechanical properties of poly(vinylidene fluoride-co-hexafluoropropylene) actuators were investigated using a non-activated multi-walled carbon nanotube (MWCNT)-ionic liquid (IL) gel electrode containing manganese oxide $\left(\mathrm{MnO}_{2}\right)$ on various ILs. The $\mathrm{MnO}_{2} / \mathrm{MWCNT} / \mathrm{IL}$ actuators surpassed the strain and maximum generated stress performance observed for the only-MWCNT and onlySWCNT actuators on all ILs. These actuators are different from only-MWCNT and only-SWCNT actuators, which act solely as electrostatic double-layer capacitor (EDLC) units. The frequency dependence of the displacement responses of the $\mathrm{MnO}_{2} \cdot x \mathrm{H}_{2} \mathrm{O} / \mathrm{MWCNT/IL}$ polymer actuators was successfully simulated using a double-layer charging kinetic model. Two parameters for the simulation were determined: the strain at the low frequency limit and the time constant. Simulations of the electromechanical response of the $\mathrm{MnO}_{2} \cdot x \mathrm{H}_{2} \mathrm{O} / \mathrm{MWCNT/IL}$ actuators predicted strains at low frequencies as well as at the associated time constant, confirming that the model is applicable not only to EDLC-based actuator systems but also to the fabricated EDLC/FC system. These results suggest that flexible, robust films, fabricated from metal oxides and MWCNTs that function synergistically, are potential candidates for actuator materials that can be applied in wearable and energy conversion devices.
\end{abstract}

Received 5th April 2016 Accepted 5th July 2016 DOI: $10.1039 / c 6 r a 08676 d$ www.rsc.org/advances properties that make them quite applicable in quick-response actuators as well as in highly electrochemically stable devices, including low volatility, high ionic conductivity, and wide potential windows. ${ }^{8}$ However, our research has found that the specific IL, nanocarbon, and polymer used in such devices can affect the resulting electromechanical and electrochemical characteristics of the actuator. ${ }^{6,9-12}$

Electrochemical capacitors (ECs) can be placed in two broad categories. The first category covers faradaic capacitors (FC) employing electrochemically active compounds such as metal oxides as electrodes. They are capable of directly storing charge throughout the charging and discharging processes. ${ }^{13-15}$ The second category includes electrostatic double-layer capacitors (EDLC) employing electrochemically inactive substances such as carbon particles as electrode materials. No electrochemical reaction occurs on the electrode surface during the charging and discharging of these devices, and therefore, only physical charge accumulates at the electrode/electrolyte interface. Regardless of the EC category, the device should have a significant surface area along with a suitable pore-size distribution, and should employ high-conductivity electrode materials to obtain the highest possible capacitance values. A third possible EC is the hybrid capacitor, ${ }^{16}$ in which both the EDLC and FC mechanisms occur simultaneously, with one being dominant. 
From the above discussion, it is evident that FCs, also known as pseudo capacitors, differ from EDLCs. The application of a potential to an FC generates rapid, reversible faradaic (or redox) reactions on the electrode surface. Conductive polymers and various metal oxides, including $\mathrm{RuO}_{2}, \mathrm{MnO}_{2}$, and $\mathrm{Co}_{3} \mathrm{O}_{4}$, are known to allow these redox reactions. ${ }^{13,17-19}$ During this process, charge moves across the double layer in a process that mimics battery charging and discharging, such that a faradaic current passes through the capacitor cell.

To the best of our knowledge, no non-activated multi-walled carbon nanotube (MWCNT) polymer actuators showing improved performance over SWCNT polymer actuators have been developed. SWCNTs are specially prepared compounds that are very expensive. MWCNTs, on the other hand, are quite inexpensive and are commonly used in battery electrodes. Carbon nanotubes (CNTs) have been recognized as potential electrode materials for supercapacitors (SCs) because of their unique properties (such as mesoporous character and good chemical stability and conductivity) and nanometer size. ${ }^{20}$ Therefore, CNT-metal oxide composites are good candidates for EDLCs because of their good charge-discharge stability. In fact, several papers have discussed CNT-Ru oxide composites. $^{21,22} \mathrm{RuO}_{2}$ is a very promising electrode material for EDLCs due to its large specific capacitance and good conductivity compared with that of other oxides. ${ }^{23,24}$ Recently, we reported that polymer actuators containing either activated MWCNT$\mathrm{COOH}$ or non-activated MWCNTs with $\mathrm{RuO}_{2}$ surpassed the performance of an SWCNT-containing actuator in terms of both strain and maximum generated stress. ${ }^{25,26}$

However, the main disadvantage in the use of $\mathrm{RuO}_{2} \cdot n \mathrm{H}_{2} \mathrm{O}$ is its high cost. Therefore, much effort has recently been devoted to finding alternative materials that are less expensive. In this sense, $\mathrm{MnO}_{2}$ is a promising SC material because of its low cost and the fact that $\mathrm{Mn}$ is more environmentally friendly than other transition metals. ${ }^{27}$ Similar to $\mathrm{RuO}_{2}, \mathrm{MnO}_{2}$ can be prepared in either hydrated or amorphous forms. Its electrical conductivity, however, is not high enough for it to be used as an electrode material for SCs. One commonly used method for producing a SC electrode using $\mathrm{MnO}_{2}$ is the electrodeposition of a thin $\mathrm{MnO}_{2}$ layer over a conductive support. Recently, we reported that the performance of polymer actuators comprising non-activated MWCNTs with $\mathrm{MnO}_{2}$ surpassed that of a SWCNTcontaining actuator, in terms of both strain and maximum generated stress, on 1-ethyl-3-methylimidazolium tetrafluoroborate $\left(\mathrm{EMI}\left[\mathrm{BF}_{4}\right]\right)$ and 1-ethyl-3-methylimidazolium bis (trifluoromethanesulfonyl)imide (EMI[TFSI]) ILs. ${ }^{28}$

Liu et al. ${ }^{29}$ demonstrated the fabrication of compact, flexible, and mechanically robust films using interpenetrating nanocomposites composed of graphene/ $\mathrm{MnO}_{2}$ and CNTs that showed superior electrochemical characteristics. These nanocomposites were intended for use as SC electrodes. Liu's approach departs from earlier works since it takes advantage of synergistic effects arising from the combination of graphene and nanotubes.

Our group has previously applied a triangular waveform voltage at various frequencies to a bucky-gel actuator as means of assessing its voltage-current and voltage-displacement

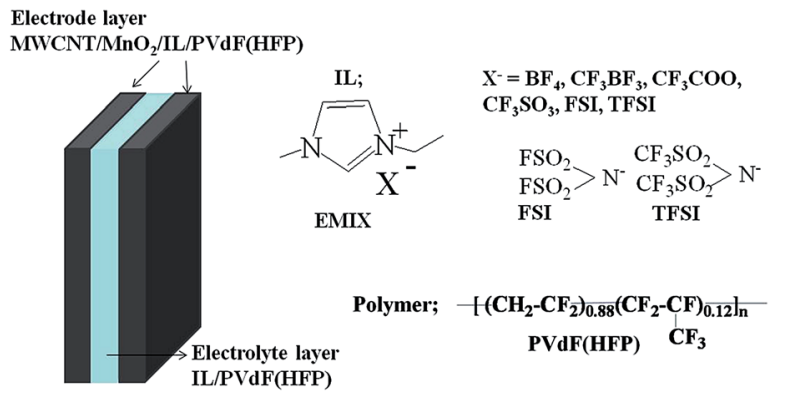

Fig. 1 Configuration of a polymer-supported $\mathrm{MnO}_{2} / \mathrm{MWCNT/IL}$ gel actuator, and molecular structures of the ILs and polymers used in this work.

characteristics. ${ }^{6,30}$ In the past, we considered that the frequency dependence of the actuator strain could be qualitatively modelled using an electrochemical equivalent circuit model based on the lumped resistance and capacitance of the electrode layer and the lumped resistance of the electrolyte layer.

In the present work, we fabricated a hybrid (electrostatic double-layer/faradaic capacitor) polymer actuator that exploits the synergistic effects resulting from the combination of MWCNTs and $\mathrm{MnO}_{2} \cdot x \mathrm{H}_{2} \mathrm{O}$. The electrochemical and electromechanical characteristics of this device were subsequently compared with those of polymer actuators fabricated using only SWCNTs or MWCNTs with various ILs (Fig. 1). The frequency dependence of the displacement responses of the $\mathrm{MnO}_{2}$ / MWCNT polymer actuators was simulated using a double-layer charging kinetic model with various ILs.

\section{Experimental}

\section{Materials}

MWCNTs (NC3150, Nanocyl Inc.) and SWCNTs (high-purity HiPco $^{\text {TM }}$ SWCNTs, Unidym Inc.) were used as received. The MWCNTS had an average diameter of $9.5 \mathrm{~nm}$ and average length of $<1 \mu \mathrm{m}$, whereas the SWCNTs had an average diameter of $\sim 0.8-$ $1.2 \mathrm{~nm}$ and average length of $\sim 0.1-1 \mu \mathrm{m}$. $\mathrm{MnO}_{2} \cdot x \mathrm{H}_{2} \mathrm{O}$ was synthesized according to the literature. ${ }^{27}$ The ILs, based on 1ethyl-3-methylimidazolium (EMI) cations and tetrafluoroborate, trifluoroacetate, triflate, bis(fluorosulfonyl)imide, or bis(trifluoromethanesulfonyl)imide anions $\left(\mathrm{EMI}\left[\mathrm{BF}_{4}\right]\right.$ (Fluka), EMI $\left[\mathrm{CF}_{3} \mathrm{COO}\right]$ (Fluka), EMI $\left[\mathrm{CF}_{3} \mathrm{SO}_{3}\right]$ (IoLiTec Ionic Liquids Technologies), EMI[FSI] (Dai-ichi Kogyo Seiyaku), and EMI[TFSI] (Merck), respectively) were also used as received; their chemical structures are shown in Fig. 1. The IL 1-ethyl-3-methylimidazolium trifluoromethyltrifluoroborate $\left(\mathrm{EMI}\left[\mathrm{CF}_{3} \mathrm{BF}_{3}\right]\right.$, Fig. 1) was synthesized according to the literature method. ${ }^{31}$ Other reagents, poly(vinylidene fluoride-co-hexafluoropropylene) (PVdF(HFP); Kynar Flex 2801, Arkema Chemicals Inc.), methyl pentanone (MP; Aldrich), propylene carbonate (PC; Aldrich), and dimethylacetamide (DMAc; Kishida Chemical Co. Ltd.) were used as received.

\section{Preparation of the actuator films ${ }^{9}$}

The configuration of the bucky-gel actuator is illustrated in Fig. 1. The polymer-supported bucky-gel electrode layer was 
typically composed of $16.7 \mathrm{wt} \%$ MWCNTs, $16.7 \mathrm{wt} \% \mathrm{MnO}_{2}$ $\cdot x \mathrm{H}_{2} \mathrm{O}, 40 \mathrm{wt} \% \mathrm{IL}$, and $26.6 \mathrm{wt} \% \mathrm{PVdF}(\mathrm{HFP})$, and was prepared as follows. The MWCNTs $(50 \mathrm{mg}), \mathrm{MnO}_{2} \cdot x \mathrm{H}_{2} \mathrm{O}(50 \mathrm{mg}), \mathrm{IL}$ (120 mg), and PVdF(HFP) (80 mg) were dispersed in DMAc (9 $\mathrm{mL}$ ) using ultrasonication for more than $5 \mathrm{~h}$. A gelatinous mixture was then obtained. The electrode layer was fabricated by casting $1.6 \mathrm{~mL}$ of the electrode mixture in a Teflon mould $\left(2.5 \times 2.5 \mathrm{~cm}^{2}\right)$ and evaporating the solvent. The solvent was then completely removed in vacuo at $80^{\circ} \mathrm{C}$. The thickness of the obtained electrode film was 70-80 $\mu \mathrm{m}$. Each gel electrolyte layer was then fabricated by combining an IL and PVdF(HFP) (0.5 $\mathrm{mmol} / 100 \mathrm{mg})$ with a mixture of MP $(1 \mathrm{~mL})$ and PC $(250 \mathrm{mg})$, and casting a portion of the solution $(0.3 \mathrm{~mL})$ in a Teflon mould $\left(2.5 \times 2.5 \mathrm{~cm}^{2}\right)$, followed by solvent evaporation, and complete removal of the solvent in vacuo at $80{ }^{\circ} \mathrm{C}$. The thickness of the obtained gel electrolyte film was $20-30 \mu \mathrm{m}$. The actuator film was fabricated by hot-pressing the electrode and electrolyte layers with the same IL. The typical thickness of the actuator film was $150-175 \mu \mathrm{m}$, which is smaller than the sum of the two electrode and one electrolyte layer thicknesses, because the thickness of each layer was decreased by hot-pressing.

\section{Displacement measurements ${ }^{32}$}

The actuator experiments were conducted by an applying a triangular voltage to a $10 \times 1 \mathrm{~mm}^{2}$ actuator strip clipped by two gold disk electrodes. The displacement, at a point $5 \mathrm{~mm}$ away (free length) from the fixed point, was continuously monitored from one side of the actuator strip with a laser displacement meter (Keyence, LC2100/2220). A potentio/ galvanostat (Hokuto Denko, HA-501 G) and a waveform generator (Yokogawa Electric, FC 200) were used to activate the buckygel actuator. The electrical parameters were simultaneously measured. The measured displacement $\delta$ was transformed into the strain difference between the two bucky-gel electrode layers $(\varepsilon)$ by using the following equation, on the assumption that the cross sections are plane planar at any position along the actuator, i.e. there is no distortion of the cross section:

$$
\varepsilon=2 d \delta /\left(L^{2}+\delta^{2}\right)
$$

where $L$ is the free length and $d$ is the thickness of the actuator strip. ${ }^{33}$

\section{Characterization of the electrode and electrolyte}

Fourier-transform infrared (FT-IR) spectra were collected using the attenuated total reflection (ATR) technique with a Cary 640 FT-IR spectrometer (Agilent Technologies). X-Ray diffraction (XRD) analysis was carried out to elucidate the crystal structure of the electrodes using a Rigaku X-ray diffractometer with $\mathrm{Cu} \mathrm{K} \alpha$ radiation. X-Ray photoelectron spectroscopy (XPS) analysis was carried out to evaluate the chemical state of the electrodes using a PHI 5000 VersaProbe XPS instrument equipped with an ULVAC-PHI source using monochromated $\mathrm{Al} \mathrm{K} \alpha$ radiation. The morphologies of the electrode films were observed by scanning electron microscopy (SEM) with a JEOL JSM-6510 instrument. Young's moduli for the electrodes were estimated from the stress-strain curves, which were measured using a Seiko TMA/SS 6000 thermal stress-strain instrument.

The specific capacitance of each polymer-supported buckygel electrode ( $\phi 7 \mathrm{~mm}$ ) was estimated by cyclic voltammetry (CV), which was measured using a two-electrode configuration with a potentiostat (Hokuto Denko, HSV-100). The electrical conductivities of the electrodes were evaluated using the fourprobe DC current method, where a linear sweep wave of current was applied from the outer probe electrodes, and the voltage was measured by the inner probe electrodes. Currentvoltage curves were obtained using a potentio/galvanostat (Hokuto Denko, HA-151) with a waveform generator (Yokogawa Electric, FC 200). The conductivity of the gel electrolyte layer was assessed by impedance measurement, which was performed using a Solartron 1250 Impedance Analyser.

\section{Results and discussion}

\section{Chemical structure, morphology, and mechanical properties of the electrodes}

The FT-IR spectrum of the $\mathrm{MnO}_{2} / \mathrm{MWCNT} / \mathrm{EMI}\left[\mathrm{BF}_{4}\right] / \mathrm{PVdF}(\mathrm{HFP})$ $\left(\mathrm{MnO}_{2}:\right.$ MWCNT $\left.=1: 1\right)$ electrode is shown in Fig. 2(a). The spectrum exhibits peaks characteristic of PVdF(HFP), as expected: at 879 and $1053 \mathrm{~cm}^{-1}$ for the $-\mathrm{CF}_{2}$ stretching mode, and at 748,1170 , and $1402 \mathrm{~cm}^{-1}$ owing to the presence of the $\alpha$ phase in the PVdF(HFP). ${ }^{34}$ In addition, the FT-IR spectrum displays a peak at $839 \mathrm{~cm}^{-1}$, which is associated with the $\beta$ phase of PVdF(HFP). These results imply that this electrode is

a)

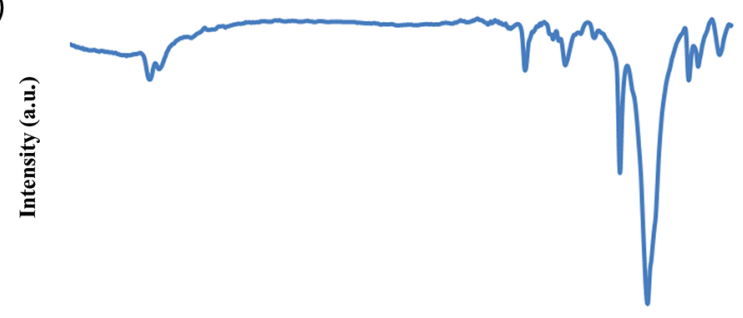

$3500 \quad 3250300027502500225020001750150012501000 \quad 750 \quad 500$ Wavenumbers $\left(\mathrm{cm}^{-1}\right)$

b)

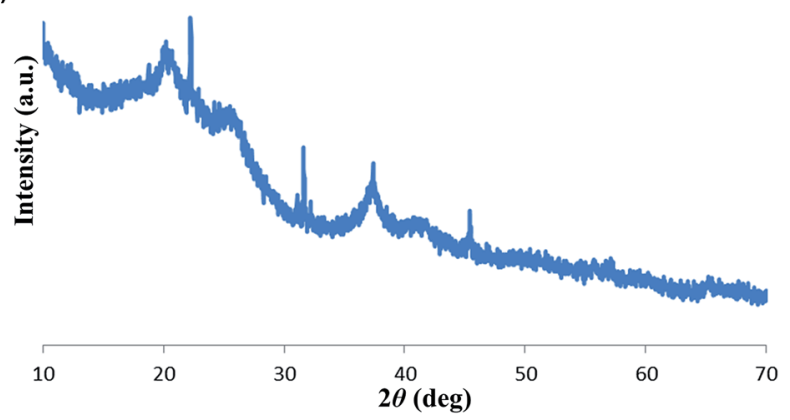

Fig. 2 (a) FT-IR spectrum and (b) X-ray diffraction pattern for the $\mathrm{MnO}_{2} / \mathrm{MWCNT} \mathrm{EMI}\left[\mathrm{BF} \mathrm{F}_{4}\right] / \mathrm{PVdF}(\mathrm{HFP})\left(\mathrm{MnO}_{2}: \mathrm{MWCNT}=1: 1\right)$ electrode (composition $=16.7 \mathrm{wt} \% \mathrm{MWCNTs}, 16.7 \mathrm{wt} \% \mathrm{MnO}_{2} \cdot \mathrm{xH}_{2} \mathrm{O}$, $40 \mathrm{wt} \% \mathrm{EMI}\left[\mathrm{BF}_{4}\right]$, and $26.6 \mathrm{wt} \% \mathrm{PVdF}(\mathrm{HFP})$ ). 
composed of a mixture of $\alpha$ - and $\beta$-phases of PVdF(HFP). The peaks at 1572,3122 , and $3162 \mathrm{~cm}^{-1}$ are attributed to the presence of $[\mathrm{EMI}]^{+}$. The spectra for the other IL-based polymersupported bucky-gel electrodes display similar features.

The XRD results obtained for the electrodes were in good agreement with the FT-IR results. The XRD pattern for the $\mathrm{MnO}_{2} / \mathrm{MWCNT} / \mathrm{EMI}\left[\mathrm{BF}_{4}\right] / \mathrm{PVdF}(\mathrm{HFP})\left(\mathrm{MnO}_{2}: \mathrm{MWCNT}=1: 1\right)$ electrode is shown in Fig. 2(b). The electrode exhibits characteristic peaks for $\mathrm{PVdF}(\mathrm{HFP})$, with major crystalline peaks at $2 \theta$ $=31.1^{\circ}$ and $20.1^{\circ}$ which correspond to the (110) crystalline planes of the $\alpha$-phase. ${ }^{35}$ The carbon materials show typical peaks at $2 \theta=22.2^{\circ}, 24.6^{\circ}$, and $45.4^{\circ} .^{36}$ Suggesting its amorphous nature, the $\mathrm{MnO}_{2}$ film shows weak peaks at $2 \theta=37.4^{\circ}$ and $65.5^{\circ} \cdot{ }^{37}$ The X-ray patterns of the other IL-based polymersupported bucky-gel electrodes show the same features.

The electrode films were characterized by XPS. Fig. $\mathrm{S} 1 \dagger$ presents a comparison of the XPS spectra for $\mathrm{MnO}_{2} / \mathrm{MWCNT} / \mathrm{IL} /$ PVdF(HFP) electrodes with different $\mathrm{MnO}_{2}:$ MWCNT ratios $(1: 1,0: 1)$ and ILs $\left(\mathrm{EMI}\left[\mathrm{BF}_{4}\right], \operatorname{EMI}\left[\mathrm{CF}_{3} \mathrm{SO}_{3}\right]\right)$. In Fig. S1(a),$\dagger$ clear peaks for $\mathrm{Mn}_{2} \mathrm{p}_{1 / 2}(655 \mathrm{eV})$ and $\mathrm{Mn} 2 \mathrm{p}_{3 / 2}(642 \mathrm{eV})$ are observed for (A) $\left(\mathrm{MnO}_{2}:\right.$ MWCNT $\left.=1: 1\right)$, whereas no peaks due to $\mathrm{Mn}$ are observed for $(\mathrm{B})\left(\mathrm{MnO}_{2}: \mathrm{MWCNT}=0: 1\right)$. The XPS spectra of the other IL-based polymer-supported bucky-gel electrodes show the same features. Fig. S1(b) $\dagger$ shows a pair of $\mathrm{S} 2 \mathrm{p}_{1 / 2}$ and $\mathrm{S} 2 \mathrm{p}_{3 / 2}$ peaks for the $\mathrm{EMI}\left[\mathrm{CF}_{3} \mathrm{SO}_{3}\right]$-based electrode (A), whereas no corresponding peaks are observed for the $\mathrm{EMI}\left[\mathrm{BF}_{4}\right]$ based sample (B). In the O1s region (Fig. S1(c) $\dagger(\mathrm{A}-\mathrm{C})$ ), peaks are individually observed for the $\mathrm{CF}_{3} \mathrm{SO}_{3}{ }^{-}$groups in $\mathrm{MnO}_{2} /$ MWCNT/EMI $\left[\mathrm{CF}_{3} \mathrm{SO}_{3}\right] / \mathrm{PVdF}(\mathrm{HFP}) \quad\left(\mathrm{MnO}_{2}:\right.$ MWCNT $\left.=0: 1\right)$ and the $\mathrm{MnO}_{2}$ in $\mathrm{MnO}_{2} / \mathrm{MWCNT} / \mathrm{EMI}\left[\mathrm{BF}_{4}\right] / \mathrm{PVdF}(\mathrm{HFP})$ $\left(\mathrm{MnO}_{2}:\right.$ MWCNT $\left.=1: 1\right)$. The O1s peaks due to both $\mathrm{MnO}_{2}$ and $\mathrm{CF}_{3} \mathrm{SO}_{3}{ }^{-}$are observed for $\mathrm{MnO}_{2} / \mathrm{MWCNT} / \mathrm{EMI}\left[\mathrm{CF}_{3} \mathrm{SO}_{3}\right] /$ PVdF(HFP) $\left(\mathrm{MnO}_{2}:\right.$ MWCNT = $\left.1: 1\right)$. Fig. 3 presents the SEM micrographs (magnification $30000 \times$ ) of polymer-supported bucky-gel electrode layers with $\mathrm{MnO}_{2}:$ MWCNT $=0: 1$ (composition $=20 \mathrm{wt} \%$ MWCNTs, $48 \mathrm{wt} \% \mathrm{EMI}\left[\mathrm{BF}_{4}\right]$, and $32 \mathrm{wt} \%$ PVdF(HFP)) (Fig. 3(a)) and $\mathrm{MnO}_{2}:$ MWCNT = $1: 1$ (composition $=16.7 \mathrm{wt} \%$ MWCNTs, $16.7 \mathrm{wt} \% \mathrm{MnO}_{2} \cdot x \mathrm{H}_{2} \mathrm{O}, 40$ $\mathrm{wt} \% \quad \mathrm{EMI}\left[\mathrm{BF}_{4}\right]$, and $26.6 \mathrm{wt} \% \quad \mathrm{PVdF}(\mathrm{HFP})$ ) (Fig. 3(b)). $\mathrm{MnO}_{2} \cdot x \mathrm{H}_{2} \mathrm{O}$ particles can be seen near the MWCNTs in Fig. 3(b). The entangled MWCNTs (average diameter: $9.5 \mathrm{~nm}$ ) form a network of open mesopores (Fig. 3(a)), and the bulk of
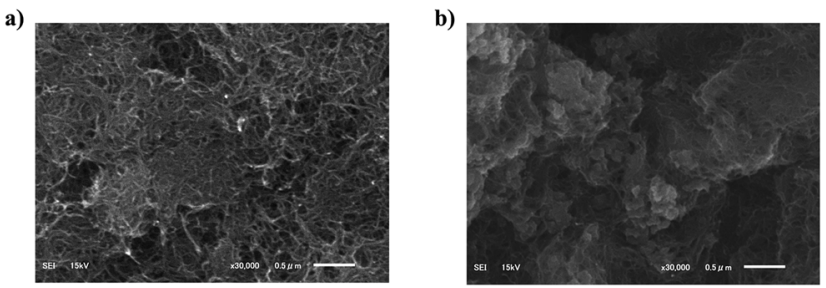

Fig. 3 SEM images (magnification $30000 \times$ ) of (a) MWCNT/EMI[BF 4$] /$ $\mathrm{PVdF}(\mathrm{HFP})\left(\mathrm{MnO}_{2}: \mathrm{MWCNT}=0: 1\right)$ electrode (composition $=20 \mathrm{wt} \%$ MWCNTs, 48 wt $\%$ EMI[BF 4 , and 32 wt\% PVdF(HFP)), and (b) $\mathrm{MnO}_{2} /$ MWCNT/EMI[BF 4$] / P V d F(H F P) \quad\left(\mathrm{MnO}_{2}:\right.$ MWCNT $\left.=1: 1\right)$ electrode (composition = $16.7 \mathrm{wt} \%$ MWCNTs, $16.7 \mathrm{wt} \% \mathrm{MnO}_{2} \cdot x \mathrm{H}_{2} \mathrm{O}, 40 \mathrm{wt} \% \mathrm{EMI}$ $\left[\mathrm{BF}_{4}\right]$, and $\left.26.6 \mathrm{wt} \% \mathrm{PVdF}(\mathrm{HFP})\right)$. the $\mathrm{MnO}_{2} \cdot x \mathrm{H}_{2} \mathrm{O}$ (average diameter: $<0.5 \mu \mathrm{m}$ ) is distributed through this network of open mesopores (Fig. 3(b)).

Fig. S2 $\uparrow$ shows the Young's moduli of the polymer-supported bucky-gel actuators containing $\mathrm{MnO}_{2} / \mathrm{MWCNT}$. For the six $\mathrm{MnO}_{2} / \mathrm{MWCNT} / \mathrm{IL}$ polymer gel electrodes, as well as the SWCNT/IL variants $\left(\mathrm{IL}=\mathrm{EMI}\left[\mathrm{BF}_{4}\right], \mathrm{EMI}\left[\mathrm{CF}_{3} \mathrm{BF}_{3}\right], \mathrm{EMI}\left[\mathrm{CF}_{3} \mathrm{COO}\right]\right.$, $\mathrm{EMI}\left[\mathrm{CF}_{3} \mathrm{SO}_{3}\right], \mathrm{EMI}[\mathrm{FSI}]$, or EMI[TFSI]), the Young's modulus values are 80-120, 90-115, 80-110, 75-100, 85-110, 80-130, and 90-175 $\mathrm{MPa}$, respectively. These results also support the entanglement of the MWCNTs to form a network of open mesopores, similar to the SWCNTs.

In this work, the use of MWCNTs is proposed as a means of improving the electrical conductivity of $\mathrm{MnO}_{2}$ electrodes used to build capacitors. The results presented herein demonstrate that MWCNTs are effective at increasing the capacitance of such devices and improving the electrochemical properties of $\mathrm{MnO}_{2}$ electrodes. This enhancement occurs because the use of MWCNT nanoparticles allows ions ready access to the $\mathrm{MnO}_{2}$ particles (Fig. S3†). These results are considered to be a result of the synergistic effect between the MWCNTs and the metal oxide. $^{29}$

\section{Electrochemical properties of the electrodes}

Fig. 4 shows the specific capacitance $C$ (where the specific capacitance of the nanocarbon, $C_{\text {nanocarbon }}=C_{1} /$ (weight of nanocarbon)) of the polymer-supported bucky-gel electrodes as a function of the CNT content and type of IL. The specific capacitance values of the $\mathrm{MnO}_{2} /$ MWCNT electrodes are larger than those of the electrodes containing only MWCNTs (referred to as only-MWCNT), and are proportional to the amount of $\mathrm{MnO}_{2}$ used. The specific capacitances for the $\mathrm{MnO}_{2} / \mathrm{MWCNT} /$ $\mathrm{EMI}\left[\mathrm{BF}_{4}\right]$ or $\left[\mathrm{CF}_{3} \mathrm{SO}_{3}\right]\left(\mathrm{MnO}_{2}: \mathrm{MWCNT}=0.25,0.5\right.$, and 1.0) and $\mathrm{MnO}_{2} / \mathrm{MWCNT} /\left(\mathrm{EMI}\left[\mathrm{CF}_{3} \mathrm{BF}_{3}\right], \quad \mathrm{EMI}\left[\mathrm{CF}_{3} \mathrm{COO}\right], \quad \mathrm{EMI}[\mathrm{FSI}]\right.$, and $\mathrm{EMI}[\mathrm{TFSI}])\left(\mathrm{MnO}_{2}: \mathrm{MWCNT}=0.5\right.$ and 1.0) electrodes are larger than the those for the corresponding only-SWCNT electrodes. The specific capacitance values of the $\mathrm{MnO}_{2} / \mathrm{MWCNT} / \mathrm{IL}$ $\left(\mathrm{MnO}_{2}:\right.$ MWCNT $\left.=1.0\right)$ electrodes follow the order $\left[\mathrm{BF}_{4}\right]>$ $\left[\mathrm{CF}_{3} \mathrm{COO}\right]$ and $\left[\mathrm{CF}_{3} \mathrm{SO}_{3}\right]>\left[\mathrm{CF}_{3} \mathrm{BF}_{3}\right]$, [FSI], and [TFSI], and thus

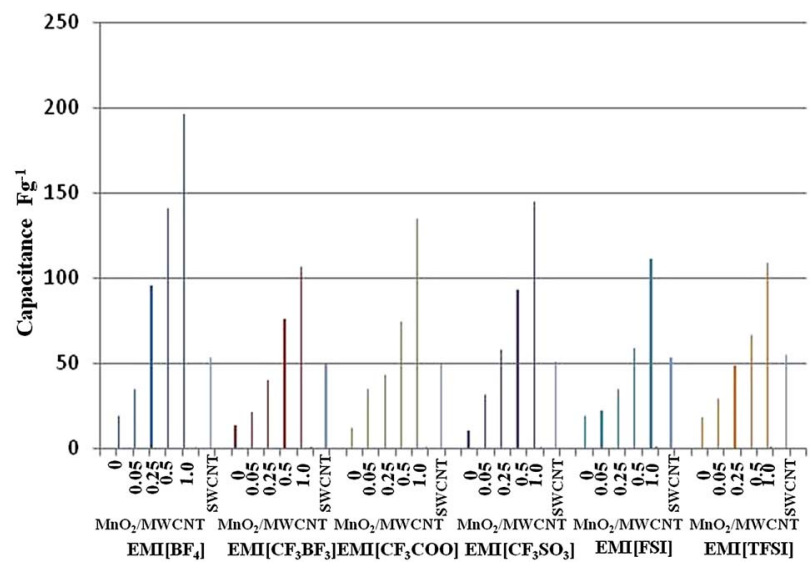

Fig. 4 Specific capacitance, $C$, of $\mathrm{MnO}_{2} / \mathrm{MWCNT}$ in polymer-supported IL gel electrodes for various $\mathrm{MnO}_{2}$ : MWCNT ratios (applied triangular voltage $= \pm 0.5 \mathrm{~V}$, sweep rate $=1 \mathrm{mV} \mathrm{s}^{-1}$ ). 
depend on the IL species in the electrode layer. The $\mathrm{MnO}_{2}$ / MWCNT electrodes containing $\mathrm{EMI}\left[\mathrm{BF}_{4}\right]$ have the largest specific capacitance values of all systems described. These higher values are believed to result from a more optimized pore size distribution in the $\mathrm{EMI}\left[\mathrm{BF}_{4}\right]$ electrodes.

It is believed that the specific capacitance of the $\mathrm{MnO}_{2} /$ MWCNT electrode results from both EDLC and FC mechanisms, with the FC mechanism providing the largest contribution. This combination of mechanisms differs from the capacitance mechanism in the electrodes made solely with MWCNTs or SWCNTs. Furthermore, this combined mechanism is considered to result from the synergistic effect between the MWCNTs and metal oxide. ${ }^{29}$ The energy storage mechanism associated with these oxides is based primarily on fast faradaic redox reactions that occur between the oxide and the electrolyte $^{38,39}$ that give rise to pseudo capacitance. Therefore, electrodes with these oxides can store more energy than the onlyMWCNT electrodes used in typical specific capacitors. ${ }^{38}$ Consequently, these results may be largely attributed to the pseudo capacitance of the $\mathrm{MnO}_{2}$ species, which can be oxidized and reduced reversibly through the reaction presented in eqn (2). ${ }^{23}$

$$
\mathrm{MnO}_{2}+\delta \mathrm{EMI}^{+}+\delta \mathrm{e}^{-}=\mathrm{MnO}_{2-\delta}(\mathrm{OEMI})_{\delta},(0<\delta<2)
$$

Fig. $\mathrm{S} 4 \dagger$ shows the electrical conductivities of various polymer-supported nanocarbon/IL gel electrode layers containing $\mathrm{MnO}_{2}$ as a function of the CNT content and type of IL. For the six $\mathrm{MnO}_{2} / \mathrm{MWCNT} / \mathrm{IL}$ polymer gel electrodes, as well as the SWCNT/IL variants ( $\mathrm{IL}=\mathrm{EMI}\left[\mathrm{BF}_{4}\right], \mathrm{EMI}\left[\mathrm{CF}_{3} \mathrm{BF}_{3}\right], \mathrm{EMI}$ $\left[\mathrm{CF}_{3} \mathrm{COO}\right], \mathrm{EMI}\left[\mathrm{CF}_{3} \mathrm{SO}_{3}\right], \mathrm{EMI}[\mathrm{FSI}]$, or EMI[TFSI]), the electrical conductivity values are $7-11,10-17,9-11,12-17,11-17,12-14$, and 13-19 $\mathrm{S} \mathrm{cm} \mathrm{cm}^{-1}$, respectively. Therefore, the electrical conductivity depends on the composition of the IL species in the electrode layer.

\section{Electromechanical properties and performance of the actuators}

Fig. 5 shows the strain as a function of the applied triangular voltage $( \pm 2 \mathrm{~V})$ for actuators containing different polymersupported $\mathrm{CNT} / \mathrm{EMI}\left[\mathrm{CF}_{3} \mathrm{SO}_{3}\right]$ bucky-gel electrodes. The strain is dependent on the measured frequency, as the CNTs dispersed in the electrode layer are fully charged at low frequencies (0.05$0.005 \mathrm{~Hz}$ ). In contrast, at higher frequencies, there is not enough time for the dispersed CNTs to become fully charged. ${ }^{6}$ The strains in the other IL-based polymer-supported bucky-gel actuators show the same trends. The strains of the $\mathrm{MnO}_{2}$ / MWCNT actuators (over 100-0.005 Hz) are greater than that of the only-MWCNT actuator. Furthermore, the strain of the $\mathrm{MnO}_{2}: \mathrm{MWCNT}=1.0$ actuator (over the frequency range of 1$0.005 \mathrm{~Hz}$ ) is larger than that of the only-SWCNT actuator. At low frequencies $(0.05-0.005 \mathrm{~Hz})$, the specific capacitance of the $\mathrm{MnO}_{2} / \mathrm{MWCNT}$ electrode exceeds that of the only-MWCNT electrode. It appears that the specific capacitance values of the $\mathrm{MnO}_{2} / \mathrm{MWCNT}$ electrodes originate from both EDLC and FC mechanisms, with the greatest contribution coming from the

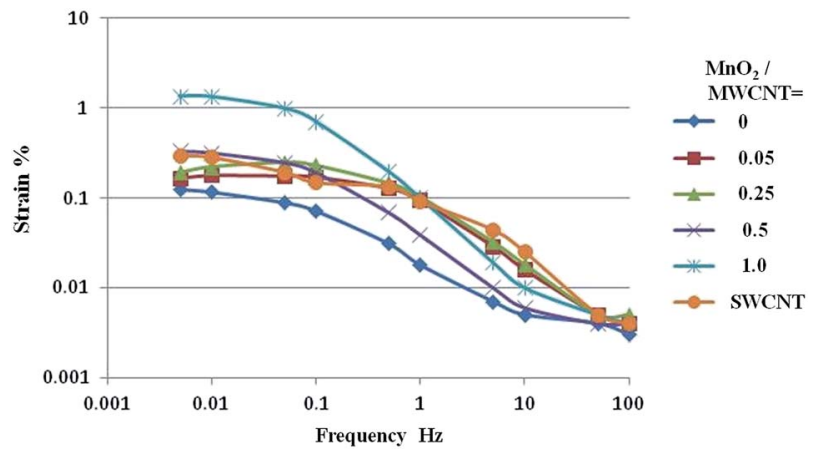

Fig. 5 Strain calculated from the peak-to-peak values of the displacements of the polymer-supported CNT/IL gel actuators for various $\mathrm{MnO}_{2}$ : MWCNT ratios as a function of the applied triangular voltage $( \pm 2 \mathrm{~V})\left(\mathrm{IL}=\mathrm{EMI}\left[\mathrm{CF}_{3} \mathrm{SO}_{3}\right]\right)$.

FC mechanism. This differs from the only-MWCNT or onlySWCNT electrodes.

The maximum strain values for the $\mathrm{MnO}_{2}:$ MWCNT $=0.5$ and 1.0, only-MWCNT, and only-SWCNT actuators (0.56-0.95\%, $0.84-1.85 \%$, $0.09-0.26 \%$, and $0.20-0.43 \%$, respectively) are shown in Table 1 . With respect to the IL species, the maximum strains for the $\mathrm{MnO}_{2}:$ MWCNT $=0.5$ actuators follow the order $\left[\mathrm{CF}_{3} \mathrm{SO}_{3}\right]>\left[\mathrm{BF}_{4}\right]>\left[\mathrm{CF}_{3} \mathrm{COO}\right]$ and $[\mathrm{TFSI}]>\left[\mathrm{CF}_{3} \mathrm{BF}_{3}\right]>[\mathrm{FSI}]$, and the order for the $\mathrm{MnO}_{2}: \mathrm{MWCNT}=1.0$ devices is $\left[\mathrm{CF}_{3} \mathrm{SO}_{3}\right]>$ $\left[\mathrm{BF}_{4}\right]>\left[\mathrm{CF}_{3} \mathrm{COO}\right]>[\mathrm{TFSI}]>\left[\mathrm{CF}_{3} \mathrm{BF}_{3}\right]>[\mathrm{FSI}]$. For all the metal oxide-carbon composite actuators, regardless of the IL, the strains are greater than those of the only-MWCNT actuators. Furthermore, the strains of the $\mathrm{MnO}_{2}:$ MWCNT $=0.5$ and 1.0 actuators are greater than those of the corresponding onlySWCNT actuators. The maximum strains of the $\mathrm{MnO}_{2}: \mathrm{MWCNT}=1.0$ actuators in $\mathrm{EMI}\left[\mathrm{BF}_{4}\right]{ }^{28} \mathrm{EMI}\left[\mathrm{CF}_{3} \mathrm{BF}_{3}\right]$, $\mathrm{EMI}\left[\mathrm{CF}_{3} \mathrm{COO}\right], \mathrm{EMI}\left[\mathrm{CF}_{3} \mathrm{SO}_{3}\right], \mathrm{EMI}[\mathrm{FSI}]$, and EMI[TFSI] are larger by factors of $4,2.3,6.7,6.2,3.3$, and 3.5 compared to the SWCNT actuators in the equivalent IL. The maximum strain values of the MWCNT electrodes containing $\mathrm{MnO}_{2}$ are larger than those of the only-MWCNT and only-SWCNT actuators, and similarly, the specific capacitance values of the $\mathrm{MnO}_{2} / \mathrm{MWCNT}$ electrodes are larger than those of the only-MWCNT and only-SWCNT electrodes. Most likely, the specific capacitances of the $\mathrm{MnO}_{2}$ / MWCNT/IL electrodes are the result of both EDLC and FC effects, with the largest capacitance contribution coming from

Table 1 Comparison of the maximum strains (\%) of polymer-supported $\mathrm{MnO}_{2} / \mathrm{MWCNT} / \mathrm{IL}=0.5$ and 1.0, only-MWCNT/IL, and onlySWCNT/IL gel actuators

\begin{tabular}{lllll}
\hline $\mathrm{IL}$ & $\begin{array}{l}\mathrm{Mn}_{2} \mathrm{O} / \\
\mathrm{MWCNT}=0.5\end{array}$ & $\begin{array}{l}\mathrm{Mn}_{2} \mathrm{O} / \\
\mathrm{MWCNT}=1.0\end{array}$ & MWCNT & SWCNT \\
\hline $\mathrm{BF}_{4}$ & 0.88 & 1.67 & 0.09 & 0.42 \\
$\mathrm{CF}_{3} \mathrm{BF}_{3}$ & 0.73 & 0.99 & 0.24 & 0.43 \\
$\mathrm{CF}_{3} \mathrm{COO}$ & 0.76 & 1.35 & 0.12 & 0.20 \\
$\mathrm{CF}_{3} \mathrm{SO}_{3}$ & 0.95 & 1.85 & 0.13 & 0.30 \\
$\mathrm{FSI}^{\mathrm{TFSI}}$ & 0.56 & 0.84 & 0.26 & 0.26 \\
& 0.77 & 1.23 & 0.13 & 0.34
\end{tabular}


the FC mechanism. It appears that an additional factor other than the FC effect contributes to the strain.

Fig. 6 compares the maximum generated stresses of the polymer-supported bucky-gel actuators containing $\mathrm{MnO}_{2} /$ MWCNTs with the SWCNT-based actuators. The maximum generated stress $(\sigma)$ during actuation was calculated from the maximum strain $\left(\varepsilon_{\max }\right)$ and Young's modulus $(Y)$, according to Hooke's law, $\sigma=Y \times \varepsilon_{\max }$. The maximum stresses generated by the $\mathrm{MnO}_{2} / \mathrm{MWCNT}$ actuators exceed those of the only-MWCNT actuators. In addition, the maximum stresses generated by the $\mathrm{MnO}_{2}: \mathrm{MWCNT}=0.5$ and 1.0 actuators are greater than those of the only-SWCNT actuators. In terms of the IL species, the maximum generated stresses for the $\mathrm{MnO}_{2}:$ MWCNT $=1.0$ actuators follow the order $\left[\mathrm{CF}_{3} \mathrm{COO}\right]>\left[\mathrm{BF}_{4}\right]>[\mathrm{TFSI}]>\left[\mathrm{CF}_{3} \mathrm{SO}_{3}\right]$ $\gg\left[\mathrm{CF}_{3} \mathrm{BF}_{3}\right]>[\mathrm{FSI}]$. More interestingly, the $\sigma$ values for the $\mathrm{MnO}_{2}:$ MWCNT $=1.0$ actuators are ca. $1.7\left(\left[\mathrm{BF}_{4}\right]\right), c a .2 .0$ $\left(\left[\mathrm{CF}_{3} \mathrm{BF}_{3}\right]\right), c a .5 .0\left(\left[\mathrm{CF}_{3} \mathrm{COO}\right]\right), c a .3 .2\left(\left[\mathrm{CF}_{3} \mathrm{SO}_{3}\right]\right), c a .1 .6([\mathrm{FSI}])$, and $c a .2 .5$ ([TFSI]) times larger than those of the only-SWCNT actuators.

These results can be attributed to the large capacitances of these devices. At low frequencies, the strain of the $\mathrm{MnO}_{2} /$ MWCNT/IL actuator is likely the primary contributor to the pseudo capacitance of the actuator. In addition, the $\mathrm{MnO}_{2} /$ MWCNT polymer actuators fabricated in this study surpass the performance of the only-MWCNT and only-SWCNT actuators. Consequently, these results demonstrate that $\mathrm{MnO}_{2} / \mathrm{MWCNT}$ actuators prepared using common nanocarbon materials can generate sufficient strain for real-world applications (such as tactile displays), without the need for specialized SWCNTs.

\section{Actuation mechanism}

We previously proposed a mechanism for the bending of a SWCNT actuator. ${ }^{5}$ In this mechanism, the application of a voltage between the two electrode layers leads to transfer of cations and anions in the gel electrolyte layer to the cathode and anode layers, respectively, and thus forms an electric double layer with negatively and positively charged nanotubes. Such ion transport results in the swelling of the cathode layer and

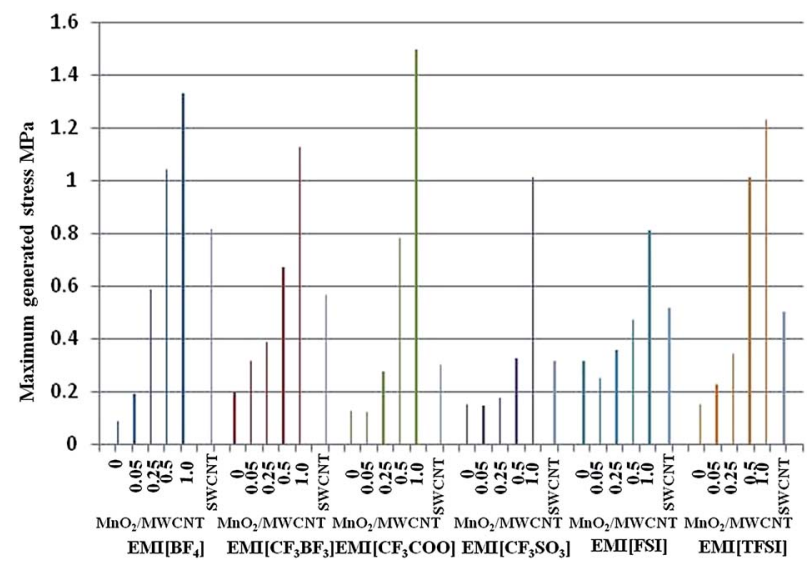

Fig. 6 Comparison of the maximum generated stress for various polymer-supported MWCNT/IL gel electrode layers containing $\mathrm{MnO}_{2}$. shrinkage of the anode layer; hence, the actuator bends towards the anode. In the present work, the capacitances of the $\mathrm{MnO}_{2} /$ MWCNT/IL devices are 22-196 $\mathrm{F} \mathrm{g}^{-1}$, while those of the MWCNT/IL electrodes are 10-19 $\mathrm{F} \mathrm{g}^{-1}$. We, therefore, propose that the contribution of the EDLC mechanism is minor at low frequencies, while that of the pseudo capacitance is predominant. As noted, in hybrid capacitors such as these, both the EDLC and FC mechanisms occur simultaneously, although one will have a more pronounced effect (Fig. 7).

Fig. $\mathrm{S} 5 \dagger$ shows a CV for a cell with the $\mathrm{EMI}\left[\mathrm{CF}_{3} \mathrm{BF}_{3}\right]$ electrolyte sandwiched between non-MWCNT-containing gel electrode layers $\left(\mathrm{MnO}_{2} \cdot x \mathrm{H}_{2} \mathrm{O} / \mathrm{EMI}\left[\mathrm{CF}_{3} \mathrm{BF}_{3}\right] / \mathrm{PVdF}(\mathrm{HFP})\right)$. The $\mathrm{CV}$ exhibits a capacitive wave at this sweep rate $=40 \mathrm{mV} \mathrm{s}^{-1}(0.005 \mathrm{~Hz})$; similar CVs were obtained for the other IL-based cell systems. The capacitances of the $\mathrm{EMI}\left[\mathrm{BF}_{4}\right]-, \mathrm{EMI}\left[\mathrm{CF}_{3} \mathrm{BF}_{3}\right]$-, $\mathrm{EMI}\left[\mathrm{CF}_{3} \mathrm{COO}\right]$, $\mathrm{EMI}\left[\mathrm{CF}_{3} \mathrm{SO}_{3}\right]-$, EMI[FSI]-, and EMI[TFSI]-based electrodes (without MWCNTs) are 0.565, 0.043, 0.852, 1.315, 0.020, and $0.035 \mathrm{~F} \mathrm{~g}^{-1}$, respectively, which are smaller than the specific capacitance values obtained for the only-SWCNT or $\mathrm{MnO}_{2} /$ MWCNT electrodes. Furthermore, the electrical conductivities of the $\mathrm{EMI}\left[\mathrm{BF}_{4}\right]-, \mathrm{EMI}\left[\mathrm{CF}_{3} \mathrm{BF}_{3}\right]$-, $\mathrm{EMI}\left[\mathrm{CF}_{3} \mathrm{COO}\right]-, \mathrm{EMI}\left[\mathrm{CF}_{3} \mathrm{SO}_{3}\right]$-, $\mathrm{EMI}$ [FSI]-, and EMI[TFSI]-based electrodes (without MWCNTs) are 3.5, 1.2, 8.1, 2.4, 0.7, and $1.0 \mathrm{mS} \mathrm{cm}^{-1}$, respectively, i.e. ca. 1/ $1000^{\text {th }}$ of the electrical conductivity values of the $\mathrm{MnO}_{2} / \mathrm{MWCNT}$ electrodes. Therefore, MWCNTs are required to obtain the desired high specific capacitance and electrical conductivity.

Fig. 8 compares the strain calculated from the peak-topeak values of the displacement as a function of the applied triangular voltage $( \pm 2 \mathrm{~V})$ for the polymer-supported CNT/EMI $\left[\mathrm{CF}_{3} \mathrm{BF}_{3}\right]$ gel actuators with the polymer-supported nonMWCNT/EMI $\left[\mathrm{CF}_{3} \mathrm{BF}_{3}\right]$ gel actuators containing $\mathrm{MnO}_{2}$. The strain of the non-CNT/IL gel actuator containing $\mathrm{MnO}_{2}$ is less than those of the only-MWCNT and $\mathrm{MnO}_{2} / \mathrm{MWCNT}$ actuators. The strains in the other polymer-supported nanocarbon/IL gel actuators show the same trends. Therefore, the actuator should contain both MWCNTs and $\mathrm{MnO}_{2}$ to demonstrate performance that surpasses that of the SWCNT polymer actuator.

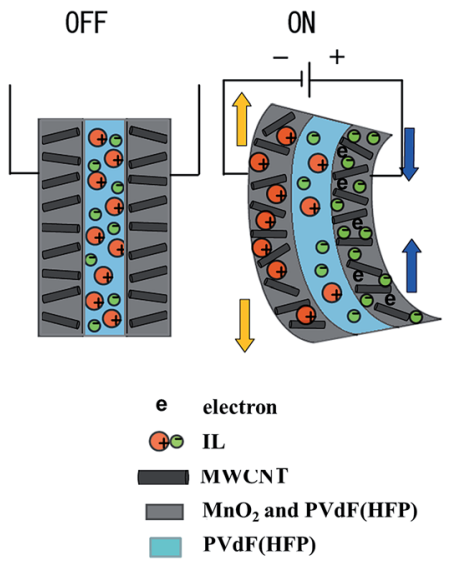

Fig. 7 Schematic of the response model for actuators based on the oxidation-reduction mechanism. 


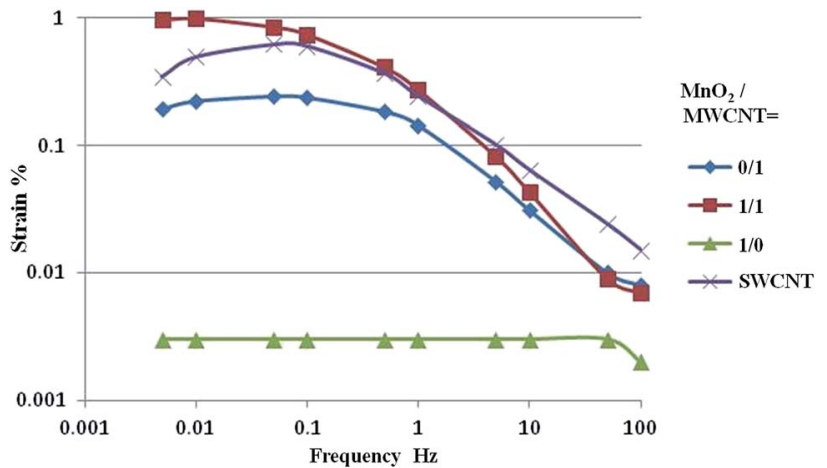

Fig. 8 Comparison of the strain calculated from the peak-to-peak values of the displacement as a function of the applied triangular voltage $( \pm 2 \mathrm{~V})$ for the polymer-supported nanocarbon/EMI[CF $\left.\mathrm{BF}_{3}\right]$ gel actuator and the polymer-supported non-nanocarbon/EMI $\left[\mathrm{CF}_{3} \mathrm{BF}_{3}\right]$ gel actuator containing $\mathrm{MnO}_{2}$.

\section{Electromechanical simulation of the actuators}

In a previous study, ${ }^{6,30}$ the voltage-current and voltagedisplacement characteristics of a bucky-gel actuator were investigated by applying a voltage with a triangular waveform at various frequencies. From the resulting data, we found that the frequency dependence of the displacement response of carbon black (CB)/vapour-grown carbon fibre (VGCF)/IL polymer actuators could be successfully simulated using an electrochemical kinetic model similar to that used for SWCNT-based actuators. In this manner, the strain at the low-frequency limit and the time constant of the response could be predicted.

In the present study, the frequency dependence of the displacement responses of the $\mathrm{MnO}_{2} \cdot x \mathrm{H}_{2} \mathrm{O} / \mathrm{MWCNT}$ actuators was successfully simulated using a double-layer charging kinetic model. This model, which takes into account the oxidization and reduction reactions of the metal oxide, is similar to the model used previously for SWCNT-based and CB/VGCF/IL actuators. This newer model also allows the prediction of the strain at the low-frequency limit and the time constant of the response.

The time constant is represented by the equivalent circuit in a series combination of the ionic resistance $R$, specific

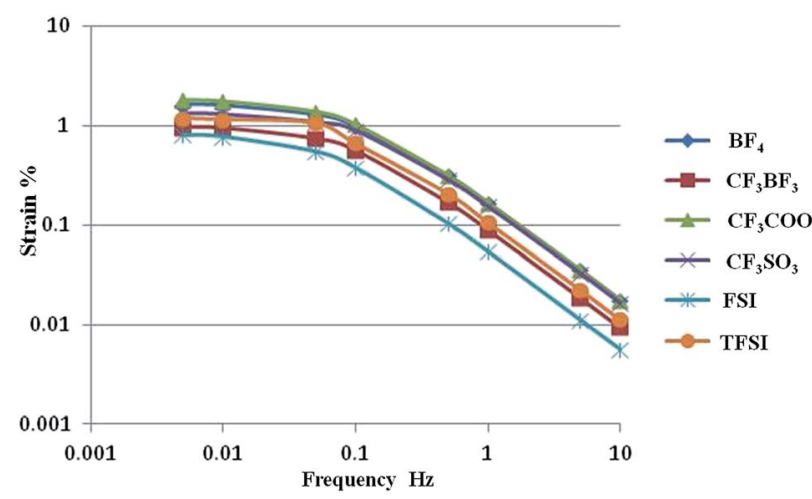

Fig. 9 Comparison of the simulated results (solid curves) for the strain dependence on the frequency of the $\mathrm{MnO}_{2} / \mathrm{MWCNT}=1.0 \mathrm{gel}$ actuator containing various ILs. capacitance $C$, and electrode resistance $R_{\mathrm{el}}$. Eqn (S1) and (S2) $\dagger$ show that strain is related to the time constant. Inspection of the simulated results (solid curves in Fig. S6†) indicates that there is a strain dependence on the frequency for the $\mathrm{MnO}_{2}$ / MWCNT $\left(\mathrm{MnO}_{2}:\right.$ MWCNT $\left.=1.0\right)$ gel actuator containing various ILs (Fig. 9). In the case of $\mathrm{MnO}_{2}$, at high frequencies $(0.1-10 \mathrm{~Hz})$, since the time constant $\left(C\left(R+R_{\mathrm{el}}\right)\right)$ trend is EMI $\left[\mathrm{CF}_{3} \mathrm{SO}_{3}\right] \fallingdotseq \mathrm{EMI}\left[\mathrm{CF}_{3} \mathrm{COO}\right] \fallingdotseq \mathrm{EMI}\left[\mathrm{BF}_{4}\right]<\mathrm{EMI}\left[\mathrm{CF}_{3} \mathrm{BF}_{3}\right] \fallingdotseq \mathrm{EMI}$ $[\mathrm{TFSI}]<\mathrm{EMI}[\mathrm{FSI}]$, the actuator strain trend is $\mathrm{EMI}\left[\mathrm{CF}_{3} \mathrm{SO}_{3}\right] \fallingdotseq$ $\mathrm{EMI}\left[\mathrm{CF}_{3} \mathrm{COO}\right] \fallingdotseq \mathrm{EMI}\left[\mathrm{BF}_{4}\right]>\mathrm{EMI}\left[\mathrm{CF}_{3} \mathrm{BF}_{3}\right] \fallingdotseq \mathrm{EMI}[\mathrm{TFSI}]>$ $\mathrm{EMI}[\mathrm{FSI}]$.

\section{Conclusions}

The electrochemical and electromechanical properties of actuators prepared using $\mathrm{MnO}_{2} / \mathrm{MWCNT} / \mathrm{IL}$ electrodes formed without ultrasonication were compared with those of actuators prepared using solely MWCNTs or SWCNTs on various ILs.

Several aspects of these new actuators were elucidated during this work, which are as follows. The electrode of this actuator system represents an EC resulting from EDLC and FC mechanisms, and the capacitance of the metal oxide $\mathrm{MnO}_{2}$ / MWCNT/IL electrode primarily results from the FC mechanism such that, at low frequencies, the strain of the $\mathrm{MnO}_{2}$ / MWCNT/IL actuator is the dominant contributor to the FC. The primary effect of the MWCNTs in this device appears to be to the increase of the electroconductivity of the $\mathrm{MnO}_{2} / \mathrm{MWCNT} /$ IL actuator. The process by which these $\mathrm{MnO}_{2} / \mathrm{MWCNT} / \mathrm{IL}$ actuators function was found to be different from that of the devices produced using solely MWCNTs or SWCNTs that incorporate only the EDLC mechanism. In addition, both $\mathrm{MO}_{2}$ and MWCNTs are required to produce actuators capable of showing significant strain that surpass the performance of SWCNT-based polymer actuators, and are thus suitable for practical applications.

The variation of the displacement with frequency for each $\mathrm{MnO}_{2} \cdot x \mathrm{H}_{2} \mathrm{O} / \mathrm{MWCNT}$ actuator was determined based on simulations employing a double-layer charging kinetic model that incorporated the oxidization and reduction reactions of the metal oxide, and was also applicable to SWCNT-based actuators on all ILs.

The frequency dependence of the displacement response of the $\mathrm{MnO}_{2} / \mathrm{MWCNT}$ actuators can be successfully simulated by the double-layer charging kinetic model. The strain at the limit of low frequency is related to the electromechanical mechanism in the $\mathrm{MnO}_{2} / \mathrm{MWCNT}$ actuator. At high frequencies $(0.1-10 \mathrm{~Hz})$, the time constant depends on the IL species; therefore, the strain is considered to be related to the time constant.

Based on the data acquired in this study, flexible and robust films operating via the synergistic effects of a $\mathrm{MnO}_{2}$ combined with MWCNTs show promise as electrode materials for synthesizing wearable and energy conversion devices. This same concept can also be used with other electrochemical materials containing metal oxides for applications in energy conversion systems, allowing for an increased range of applications. 


\section{Acknowledgements}

This work was partly supported by a KAKENHI Grant-in-Aid for Scientific Research C (No. 24550264) from the JSPS.

\section{Notes and references}

1 Y. Bar-Cohen, Directions for development of the field of electroactive polymer (EAP), in Proc. SPIE 7976, Electroactive Polymer Actuators and Devices (EAPAD) 2011, ed. Y. BarCohen and F. Carpi, 2011, p. 797604, DOI: 10.1117/ 12.880056 .

2 E. Smela, Adv. Mater., 2003, 15, 481.

3 M. Shahinpoor, Electrochim. Acta, 2003, 48, 2343.

4 T. Fukushima, K. Asaka, A. Kosaka and T. Aida, Angew. Chem., Int. Ed., 2005, 44, 2410.

5 K. Mukai, K. Asaka, K. Kiyohara, T. Sugino, I. Takeuchi, T. Fukushima and T. Aida, Electrochim. Acta, 2008, 53, 5555.

6 I. Takeuchi, K. Asaka, K. Kiyohara, T. Sugino, K. Mukai, T. Fukushima and T. Aida, Electrochim. Acta, 2009, 53, 1762.

7 T. Fukushima, A. Kosaka, Y. Ishimura, T. Yamamoto, T. Takigawa, N. Ishii and T. Aida, Science, 2003, 300, 2072.

8 W. Lu, A. G. Fadeev, B. Qi, E. Smela, B. R. Mattes, J. Ding, G. M. Spinks, J. Mazurkiewicz, D. Zhou, G. G. Wallace, D. R. MacFarlane, S. A. Forsyth and M. Forsyth, Science, 2002, 297, 983.

9 N. Terasawa, I. Takeuchi and H. Matsumoto, Sens. Actuators, $B, 2009,139,624$.

10 N. Terasawa, I. Takeuchi, H. Matsumoto, K. Mukai and K. Asaka, Sens. Actuators, B, 2011, 156, 539.

11 I. Takeuchi, K. Asaka, K. Kiyohara, T. Sugino, N. Terasawa, K. Mukai and S. Shiraishi, Carbon, 2009, 47, 1373.

12 N. Terasawa, N. Ono, Y. Hayakawa, K. Mukai, T. Koga, H. Higashi and K. Asaka, Sens. Actuators, B, 2011, 160, 161.

13 B. E. Conway, Electrochemical Supercapacitors, Kluwer Academic/Plenum Press, New York, 1999.

14 B. Babakhani and D. G. Ivey, Electrochim. Acta, 2010, 55, 4014.

15 S. Sarangapani, B. V. Tilak and C. P. Chen, J. Electrochem. Soc., 1996, 143, 3791.

16 G. Wang, L. Zhang and J. Zhang, Chem. Soc. Rev., 2012, 41, 797.

17 M. S. Wu and P. C. Chiang, Electrochem. Solid-State Lett., 2004, 7, A123.
18 W. Sugimoto, H. Iwata, Y. Murakami and Y. Takasu, J. Electrochem. Soc., 2004, 151, A1181.

19 X. Dong, W. Shen, J. Gu, L. Xiong, Y. Zhu, H. Li and J. Shi, J. Phys. Chem. B, 2006, 110, 6015.

20 S. Iijima, Nature, 1991, 354, 56.

21 A. Girish, W. Deepali, K. Mahesh, I. S. Mulla, S. P. Vernekar, K. Vijiyamohanan and A. M. Rao, Chem. Phys. Lett., 2003, 376, 207.

22 X. Qin, S. Durbach and G. T. Wu, Carbon, 2004, 42, 451.

23 J. P. Zheng and T. R. Jow, J. Electrochem. Soc., 1995, 142, L6.

24 T. C. Liu, W. G. Pell and B. E. Conway, Electrochim. Acta, 1997, 42, 3541.

25 N. Terasawa, N. Ono, K. Mukai, T. Koga, H. Higashi and K. Asaka, Carbon, 2012, 50, 311.

26 N. Terasawa, K. Mukai, K. Yamato and K. Asaka, Carbon, 2012, 50, 1888.

27 H. Y. Lee and J. B. Goodenough, J. Solid State Chem., 1999, 144, 220.

28 N. Terasawa, K. Mukai, K. Yamato and K. Asaka, Sens. Actuators, B, 2012, 171-172, 595.

29 Y. Cheng, S. Lu, H. Zhang, C. V. Varanasi and J. Liu, Nano Lett., 2012, 12, 4206.

30 N. Terasawa and I. Takeuchi, Electrochim. Acta, 2014, 123, 340.

31 Z. B. Zhou, M. Takeda and M. Ue, J. Fluorine Chem., 2004, 125, 127.

32 N. Terasawa and I. Takeuchi, Sens. Actuators, B, 2010, 145, 775.

33 Q. Pei and O. Inganas, J. Phys. Chem., 1992, 96, 10507.

34 J. S. Lee, K. Y. Shin, O. J. Cheong, J. H. Kim and J. Jang, Sci. Rep., 2015, 5, 7887.

35 S. Abbrent, J. Plestil, D. Hlavata, J. Lindgren, J. Tegenfeldt and A. Wendsjo, Polymer, 2001, 42, 1407.

36 A. Cao, C. Xu, J. Liang, D. Wu and B. Wei, Chem. Phys. Lett., 2001, 344, 13.

37 Y. Gao, Y. S. Zhou, M. Qian, H. M. Li, J. Redepenning, L. S. Fan, X. N. He, W. Xiong, X. Huang, M. M. Samani, L. Jiangd and Y. F. Lu, RSC Adv., 2013, 3, 20613.

38 E. Frackowiak and F. Beguin, Carbon, 2001, 39, 937.

39 B. E. Conway, V. Briss and J. Wojtowicz, J. Power Sources, 1997, 66, 1 . 